\title{
Diagnostic Accuracy of Detecting Diabetic Retinopathy by Using Digital Fundus Photographs in the Peripheral Health Facilities of Bangladesh: Validation Study
}

Tahmina Begum ${ }^{1}$, MD, MPH; Aminur Rahman², MD, MPH; Dilruba Nomani ${ }^{2}$, MSc; Abdullah Mamun ${ }^{1}$, PhD; Alayne Adams $^{3}, \mathrm{PhD}$; Shafiqul Islam ${ }^{4}, \mathrm{MD}$; Zara Khair ${ }^{5}$, MSc; Zareen Khair ${ }^{5}, \mathrm{PhD}$; Iqbal Anwar ${ }^{2}, \mathrm{MD}, \mathrm{PhD}$

${ }^{1}$ Institute for Social Science Research, The University of Queensland, Brisbane, Australia

2 icddr,b, Dhaka, Bangladesh

${ }^{3}$ McGill University, Montreal, QC, Canada

${ }^{4}$ Barisal Medical College Hospial, Barisal, Bangladesh

${ }^{5}$ The Fred Hollow Foundation, Dhaka, Bangladesh

\section{Corresponding Author:}

Tahmina Begum, MD, MPH

Institute for Social Science Research

The University of Queensland

80 Meiers Rd

Brisbane, 4068

Australia

Phone: 61469705278

Email: tahminashakera@gmail.com

\section{Abstract}

Background: Diabetic retinopathy can cause blindness even in the absence of symptoms. Although routine eye screening remains the mainstay of diabetic retinopathy treatment and it can prevent $95 \%$ of blindness, this screening is not available in many low- and middle-income countries even though these countries contribute to $75 \%$ of the global diabetic retinopathy burden.

Objective: The aim of this study was to assess the diagnostic accuracy of diabetic retinopathy screening done by non-ophthalmologists using 2 different digital fundus cameras and to assess the risk factors for the occurrence of diabetic retinopathy.

Methods: This validation study was conducted in 6 peripheral health facilities in Bangladesh from July 2017 to June 2018. A double-blinded diagnostic approach was used to test the accuracy of the diabetic retinopathy screening done by non-ophthalmologists against the gold standard diagnosis by ophthalmology-trained eye consultants. Retinal images were taken by using either a desk-based camera or a hand-held camera following pupil dilatation. Test accuracy was assessed using measures of sensitivity, specificity, and positive and negative predictive values. Overall agreement with the gold standard test was reported using the Cohen kappa statistic $(\kappa)$ and area under the receiver operating curve (AUROC). Risk factors for diabetic retinopathy occurrence were assessed using binary logistic regression.

Results: In 1455 patients with diabetes, the overall sensitivity to detect any form of diabetic retinopathy by non-ophthalmologists was $86.6 \%$ (483/558, 95\% CI 83.5\%-89.3\%) and the specificity was $78.6 \%$ (705/897, 95\% CI 75.8\%-81.2\%). The accuracy of the correct classification was excellent with a desk-based camera (AUROC $0.901,95 \%$ CI 0.88-0.92) and fair with a hand-held camera (AUROC 0.710, 95\% CI 0.67-0.74). Out of the 3 non-ophthalmologist categories, registered nurses and paramedics had strong agreement with kappa values of 0.70 and 0.85 in the diabetic retinopathy assessment, respectively, whereas the nonclinical trained staff had weak agreement $(\kappa=0.35)$. The odds of having retinopathy increased with the duration of diabetes measured in 5 -year intervals $(P<.001)$; the odds of having retinopathy in patients with diabetes for 5-10 years (odds ratio [OR] 1.81, 95\% CI 1.37-2.41) and more than 10 years (OR 3.88, 95\% CI 2.91-5.15) were greater than that in patients with diabetes for less than 5 years. Obesity was found to have a negative association $(P=.04)$ with diabetic retinopathy.

Conclusions: Digital fundus photography is an effective screening tool with acceptable diagnostic accuracy. Our findings suggest that diabetic retinopathy screening can be accurately performed by health care personnel other than eye consultants. People with more than 5 years of diabetes should receive priority in any community-level retinopathy screening program. In a 
country like Bangladesh where no diabetic retinopathy screening services exist, the use of hand-held cameras can be considered as a cost-effective option for potential system-wide implementation.

(JMIR Public Health Surveill 2021;7(3):e23538) doi: 10.2196/23538

\section{KEYWORDS}

diabetic retinopathy; diagnostic accuracy; digital fundus photograph; Bangladesh; diabetes; retinopathy; retina; opthalmology

\section{Introduction}

Diabetic retinopathy, a progressive eye complication of diabetes mellitus, which affects $9.3 \%$ of the people globally, is considered the fifth leading cause of global blindness $[1,2]$. Results from a recent systematic review estimated that globally, the prevalence of retinopathy among patients with diabetes is $35 \%$ [3]. Nearly all patients with type 1 diabetes and more than $60 \%$ of the patients with type 2 diabetes develop retinopathy within 20 years of diabetes onset [4]. However, like many other diabetic complications, retinopathy remains asymptomatic until significant damage has occurred [4,5]. Periodic eye screening is essential for diagnosing the disease in early stages and to enable timely initiation of treatment [6]. Current recommendations are that retinal screening occur once a year for all patients with diabetes and that more frequent examinations take place if abnormal findings are identified [7]. However, periodic retinal screening is not available in many low- and middle-income countries although they account for $75 \%$ of the global burden of diabetic retinopathy $[3,8]$. The reported barriers are multifactorial. A recent systematic review reported that poor knowledge and attitudes to asymptomatic eye screening are prevalent both among health care providers and patients [9]. At the health care system level, the lack of equipment, insufficiently skilled professionals, nonfunctioning referral mechanisms, and inadequate data within national management information systems are the main barriers [10]. Moreover, routine diabetic retinopathy screening is not always feasible for eye consultants, given their availability versus the load of patients with diabetes.

As an alternative to eye consultants, different cadres of non-ophthalmologists such as general practitioners, opticians, and diabetologists have been successfully involved in diabetic retinopathy screening in many high-income countries [11]. Particular attention has been focused on developing simple algorithms and technologies suitable for non-ophthalmologists. Among these screening tools, digital fundus photography has been identified as one of the best and lowest cost options [12]. A digital camera allows repeated images to be taken until the best one is captured. Final retinal images can be stored and sent for expert opinion by using a web-based interface [13]. With this technology, high-income countries have shown increased diagnostic accuracy even without pupil dilatation (mydriasis) $[12,14]$. However, the nonmydriatic approach has shown low accuracy (12\%-25\%) in the Southeast Asian context [6]. Patients having a dark iris and reporting to a hospital at an advanced age with comorbid eye diseases such as cataracts are the commonly reported explanations for poor vision in the nonmydriatic approach [6].
Like many low- and middle-income countries, Bangladesh demonstrates a substantial diabetic retinopathy disease burden and an array of health system challenges that complicate the routine implementation of diabetic retinopathy screening services. According to the International Diabetic Federation statistics, around $8.4 \%$ of the total population in Bangladesh had diabetes in 2017 [15], which puts the country among the top 10 high diabetes burden countries in the world [15]. At the same time, Bangladesh has a critical shortage and "geographic maldistribution" of health workforce with an increased concentration in urban areas even though $70 \%$ of the population resides in the rural region [16]. Eye care services are provided predominantly by ophthalmologists, and diabetic retinopathy screening programs are not readily available under the current health system [17]. Given the growing burden of diabetes in Bangladesh, blindness prevention has become a strategic priority [17]. To support this effort, the "Integrated Model of Care for Diabetic Retinopathy within the Health System of Bangladesh" was initiated as a collaborative program between the Fred Hollows Foundation (FHF), a nongovernmental organization and the Government of Bangladesh [18]. This program seeks to establish a care pathway for diabetes and diabetic retinopathy by training non-ophthalmologist health cadres to conduct diabetic retinopathy screening by using digital fundus photography [18].

The aim of this study was to test the diagnostic accuracy of detecting any grade of diabetic retinopathy by non-ophthalmologists using digital fundus cameras against the gold standard diagnosis of ophthalmologists. We also explored the risk factors of diabetic retinopathy in the rural sites under investigation.

\section{Methods}

\section{Study Setting and Design}

This validation study was conducted at the project implementation sites of FHF in 4 districts under 2 administrative divisions of Bangladesh. Six health facilities were randomly chosen from these 4 districts for our study: one medical college hospital, one district hospital, and 4 health centers of the Diabetic Association of Bangladesh (DAB). The medical college hospital and the district hospital are government-funded general hospitals that provide eye care services for patients with or without diabetes. DAB centers are autonomous health care organizations focused on the treatment of patients with diabetes only. Retinopathy screening for asymptomatic cases is not a regular clinical care option in any of these health facilities. Eye consultants were available in all government hospitals and in 1 out of the 4 DAB centers. As part of project activities, the FHF established a memorandum of understanding with the concerned health facilities to establish a diabetic retinopathy screening 
corner within the eye department to provide equipment supplies and to organize relevant local and national-level trainings on diabetic retinopathy diagnosis and treatment for hospital staff. A parallel referral mechanism linking DAB centers and the closest public health facility was also established.

\section{Diabetic Retinopathy Screening Process}

Patients with diabetes attending the outdoor eye clinic at the selected study health facilities between July 2017 and June 2018 were included as the study participants. Two different types of digital fundus photography instruments were used for diabetic retinopathy screening: a desk-based high-resolution fundus camera and a hand-held low-cost fundus camera. Initial screening was done by non-ophthalmologists such as nurses, paramedics, and nonclinical trained staff. For the gold standard diagnosis, 2 eye consultants, one from each study division, were assigned to evaluate the screening done by the non-ophthalmologists for the respective administrative divisions. The desk-based camera is used in medical colleges and district hospitals, and registered nurses and paramedics are the primary diabetic retinopathy screening providers. Hand-held cameras are used in DAB centers. Other than 1 DAB center, none could deploy their own nurses/paramedics due to the high turnover rate. Thus, new project staff were recruited from FHF, one in each of the 3 DAB centers. These were nonclinical personnel with graduate degrees in any discipline. All the nonclinical staff, including nurse and paramedics, received hands-on training for 3 days from the eye consultant in the respective study division. Nurses working in the medical college obtained an opportunity to attend a month-long training at the national level. Once the 2 eye consultants certified that images taken by the non-ophthalmologists were satisfactory and their ability to detect diabetic retinopathy from the retinal images was accurate, the formal data collection process started.

Initially, the non-ophthalmologist staff took the retinal images and performed diabetic retinopathy grading independently. A short-acting pupil dilator was used prior to taking the retinal image and then, a single-field macula-focused image was taken. Subsequently, the same study participant with a referral slip (indicating patient ID and date of diabetic retinopathy screening) was referred to the eye department of the respective district or medical college hospital to be examined by the eye consultant. Retinal images were also sent to the eye consultant through a web-based interface or a portable computer disk. The eye consultants checked the gradeability of the retinal images provided through the web-based interface and performed diabetic retinopathy grading independently. The entire screening process was double-blinded, that is, no one had access to the findings of the others. The project-appointed staff monitored the data collection and retrieved data from the hospital records with a diagnostic accuracy checklist.

\section{Sampling Strategy}

The inclusion criteria were patients with type 1 diabetes older than 18 years or with type 2 diabetes having no previous diagnosis of diabetic retinopathy and images taken from both eyes. Exclusion criteria were patients with significant physical or mental disabilities that could hamper photography and having mature cataract and corneal opacity in any eye. Considering the current facility-based prevalence of diabetic retinopathy as $27 \%$ [19], a sample size calculation was performed for sensitivity and specificity. The final sample size was the maximum of these two [20]. For the anticipated sensitivity and specificity, we considered the Canadian and British Ophthalmology Society guidelines. Both guidelines recommend at least $80 \%$ sensitivity and $90 \%-95 \%$ specificity for any alternative approach of diabetic retinopathy grading $[21,22]$. Taking all these into account, our required sample size was 1138 , and we distributed them proportionately across the 6 study health facilities, considering the patient turnover rate.

\section{Outcome Measures}

The outcome variable was the presence of any form of diabetic retinopathy in either eye of a patient, which was confirmed by the eye consultant. The Airlie house classification was used for diabetic retinopathy staging, which is a validated tool for the diabetic retinopathy screening program [22]. This classification divides the diagnosis of diabetic retinopathy into 5 stages: no diabetic retinopathy, mild nonproliferative diabetic retinopathy, moderate nonproliferative diabetic retinopathy, severe nonproliferative diabetic retinopathy, and proliferative diabetic retinopathy. A diabetic retinopathy positive case referred to a patient who had any kind of diabetic retinopathy (mild nonproliferative diabetic retinopathy/moderate nonproliferative diabetic retinopathy/severe nonproliferative diabetic retinopathy/proliferative diabetic retinopathy) in any of the two eyes.

\section{Covariates}

We considered the patient's sociodemographic and clinical characteristics, both of which have been identified as risk factors of diabetic retinopathy in the literature [3]. Among the sociodemographic features, patient age, gender, education, and occupation were considered. Clinical covariates were BMI, duration of diabetes, recent blood sugar test result, and presence of hypertension. BMI was calculated from height and weight measurements performed on the day of the clinic visit by using the following formula: weight in kilograms/height in meters squared. The World Health Organization criteria of BMI classification for Asian people was used to categorize our sample into 4 groups [23]. For diabetes test results, we considered any form of blood sugar test done within 3 months with written documentation provided by the patient during diabetic retinopathy screening. We categorized diabetes test results into normal limit and uncontrolled blood sugar by using reference values provided by the available blood glucose tests [24].

\section{Statistical Analysis}

We calculated the test accuracy of non-ophthalmologists against the gold standard value and reported measures of sensitivity (true positive diabetic retinopathy/[true positive + false negative]) and specificity (true negative diabetic retinopathy/[true negative + false positive cases]) at 95\% CI. The positive predictive values and negative predictive values were also calculated from the true diabetic retinopathy positive and diabetic retinopathy negative results out of the total positive and negative test results, respectively [25]. All diagnostic accuracy results were compared by instrument types (desk-based 
camera vs hand-held camera). Additionally, differences in diagnostic accuracy were measured across the different diabetic retinopathy grades. Overall agreement and disagreement were tested using the Cohen kappa statistic and area under the receiver operating curve (AUROC). The AUROC is an index of accuracy [26] presented as a plot of true positive rates against false positive rates for different possible cut-off points of a diagnostic test [26]. Descriptive analysis reports the distribution of the study sample by covariates. The statistical association of diabetic retinopathy positive status with all covariates were tested initially through a bivariate analysis using the chi-square test. Covariates that were significant at a $P$ value $<.05$ in bivariate analysis were included in the multivariate analysis. Binary logistic regression findings were presented as odds ratio (OR) at $95 \%$ CI. All the analyses were performed using the STATA software (Release 16, College Station, StataCorp LLC) [27].

\section{Ethics Approval}

We obtained ethical clearance from the Institutional Review Board of icddr,b, Dhaka, Bangladesh under protocol number 17003. Verbal informed consent was obtained from respective hospital authorities and study participants to access medical records. Data collected from the study participants were reported anonymously to maintain privacy and confidentiality. Study participants with poor-quality retinal images or confusing findings were referred to an eye consultant for further evaluation, and transport costs were remunerated. Any patient requiring laser treatment obtained this service from a tertiary-level public hospital free of cost.

\section{Results}

\section{Characteristics of the Participants in This Study}

In total, 1511 patients with diabetes were screened, which was slightly higher than our required sample size, and we included all of them. However, 3.7\% (56/1511) of the images (including both eyes) were of poor quality and discarded from analysis. Thus, our final analytic sample consisted of 1455 patients. The mean (SD) age of the study participants was 53.23 (11.84) years, and a slightly larger proportion of the total study participants was females. More than half of the study participants had diabetes for more than 5 years. Blood sugar test results were missing for $7.0 \%(102 / 1455)$ of the patients. Blood sugar levels were reported 2 hours after breakfast in $52.5 \%$ (764/1455) of the patients and $<1 \%(2 / 1455)$ of the patients by the hemoglobin $\mathrm{A}_{1 \mathrm{C}}$ test. The mean BMI of the patients was 25.38 (4.21). Nearly half of the patients with diabetes were screened by a nurse, and half were assessed using a desk-based camera (Table 1). 
Table 1. Characteristics of the study participants who attended diabetic retinopathy screening from July 2017 to June 2018 in 6 selected peripheral hospitals in Bangladesh ( $\mathrm{N}=1455)$.

\begin{tabular}{|c|c|}
\hline Variable of interest & Values, n (\%) \\
\hline \multicolumn{2}{|l|}{ Patient age (years) } \\
\hline$<40$ years & $247(16.98)$ \\
\hline $41-50$ years & $399(27.42)$ \\
\hline $51-60$ years & $471(32.37)$ \\
\hline$>60$ years & $338(23.23)$ \\
\hline \multicolumn{2}{|l|}{ Gender } \\
\hline Female & $814(55.95)$ \\
\hline Male & $641(44.05)$ \\
\hline \multicolumn{2}{|l|}{ Education } \\
\hline No schooling & $256(17.59)$ \\
\hline Primary school completed & 309 (21.24) \\
\hline Higher secondary and above & $890(61.17)$ \\
\hline \multicolumn{2}{|l|}{ Occupation } \\
\hline Unemployed & $1001(68.80)$ \\
\hline Service & $266(18.28)$ \\
\hline Business & $188(12.92)$ \\
\hline \multicolumn{2}{|l|}{ Body mass index } \\
\hline Normal and underweight & $429(29.71)$ \\
\hline Overweight & $632(43.77)$ \\
\hline Obese & $383(26.52)$ \\
\hline \multicolumn{2}{|l|}{ Duration of diabetes } \\
\hline$<5$ years & $513(35.26)$ \\
\hline $5-10$ years & $459(31.55)$ \\
\hline$>10$ years & $483(33.19)$ \\
\hline \multicolumn{2}{|l|}{ Blood sugar level } \\
\hline Controlled & $613(45.31)$ \\
\hline Not controlled & $740(54.69)$ \\
\hline \multicolumn{2}{|l|}{ Hypertensive patient } \\
\hline No & $659(45.29)$ \\
\hline Yes & $796(54.71)$ \\
\hline \multicolumn{2}{|l|}{ Type of non-ophthalmologist } \\
\hline Nurse & $766(52.65)$ \\
\hline Paramedics & $276(18.97)$ \\
\hline Nonclinical trained staff & $413(28.38)$ \\
\hline \multicolumn{2}{|l|}{ Instrument used } \\
\hline Hand-held camera & $576(39.59)$ \\
\hline Desk-based camera & $879(60.41)$ \\
\hline \multicolumn{2}{|c|}{ Place of training for non-ophthalmologists } \\
\hline Local & $824(56.63)$ \\
\hline National & $631(43.37)$ \\
\hline
\end{tabular}




\section{Diabetic Retinopathy Accuracy Test Results}

The prevalence of diabetic retinopathy was $38.39 \%$ (558/1455). As shown in Table 2, the diagnostic accuracy of non-ophthalmologists was $86.6 \% \quad(483 / 558,95 \% \quad$ CI $83.5 \%-89.3 \%$ ) for diabetic retinopathy positive case detection (sensitivity) and 78.6\% (705/897, 95\% CI 75.8\%-81.2\%) for diabetic retinopathy negative case detection (specificity). Further, non-ophthalmologists could correctly identify $71.6 \%$ $(483 / 675)$ of the total diabetic retinopathy positive cases and correctly exclude $90.4 \%(705 / 780)$ of the total diabetic retinopathy negative cases. As the kappa value suggested, moderate agreement was observed with the gold standard $(\kappa=0.6)$.

Table 2. Diagnostic accuracy of diabetes retinopathy by instrument type in 6 selected peripheral hospitals in Bangladesh from July 2017 to June 2018 .

\begin{tabular}{llll}
\hline Indicators & Overall proportion (\%) 95\% CI & $\begin{array}{l}\text { Hand-held camera proportion (\%) } \\
95 \% \text { CI }\end{array}$ & $\begin{array}{l}\text { Desk-based camera proportion (\%) } \\
95 \% \text { CI }\end{array}$ \\
\hline Sensitivity & $86.56(83.45-89.30)$ & $85.60(80.30-89.89)$ & $87.19(83.19-90.60)$ \\
Specificity & $78.60(75.78-81.2)$ & $56.56(51.19-61.70)$ & $93.01(90.50-95.01)$ \\
Positive predictive value & $71.56(68.78-74.10)$ & $55.19(51.89-58.40)$ & $88.50(84.89-91.30)$ \\
Negative predictive value & $90.38(88.39-92.10)$ & $86.19(81.70-89.67)$ & $92.19(89.89-93.89)$ \\
Accuracy & $81.56(79.56-83.60)$ & $67.70(63.70-71.65)$ & $90.78(88.70-92.56)$ \\
Kappa & $0.63(0.58-0.78)$ & $0.38(0.31-0.46)$ & $0.80(0.74-0.87)$ \\
\hline
\end{tabular}

Accuracy was further reported by AUROC findings. As shown in Figure 1, the ability of non-ophthalmologists to correctly classify diabetic retinopathy by using a hand-held camera was "Fair" (AUROC 0.710, 95\% CI 0.67-0.74) (Figure 1, Panel A) and "Excellent" (AUROC 0.901, 95\% CI 0.88-0.92) by using a desk-based camera (Figure 1, Panel B). We also assessed the agreement of different cadres of non-ophthalmologists against the gold standard value. Strong agreement was noted between the diabetic retinopathy classification of registered nurses and paramedics and that of the gold standard diagnosis by eye consultants, with kappa values of 0.70 and 0.85 , respectively, whereas nonclinical trained staff had weak agreement $(\kappa=0.35)$. As shown in Table 3, non-ophthalmologists were particularly good at detecting the presence or absence of diabetic retinopathy. However, their accuracy differed by the diabetic retinopathy grading status particularly across the different grades of nonproliferative diabetic retinopathy. Accuracy also varied slightly depending on the type of instrument used. A desk-based camera was more likely to identify diabetic retinopathy correctly when diabetic retinopathy was present than when it was absent. In contrast, the probability of a correct diabetic retinopathy diagnosis was lower among those with a negative diabetic retinopathy finding versus those without. Although the hand-held camera was less successful in identifying diabetic retinopathy correctly in the presence of diabetic retinopathy, the probability that a person showed a negative finding with a hand-held camera for diabetic retinopathy was lower than that with a desk-based camera. 
Figure 1. Diagnostic accuracy of digital fundus photography by area under receiver operating curve. Panel A: hand-held camera and Panel B: desk-based camera.

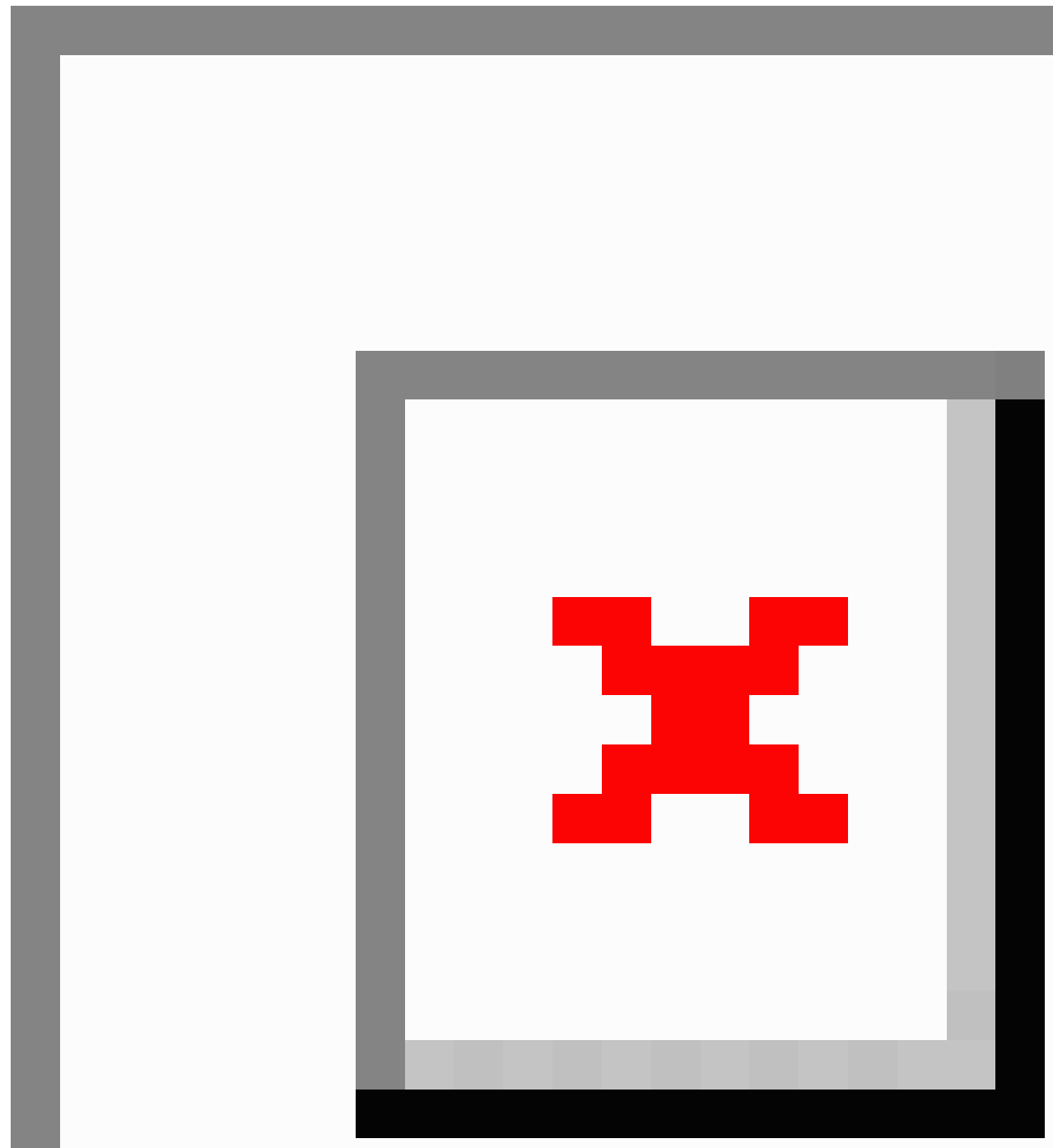


Table 3. Diagnostic accuracy of diabetic retinopathy screening by instrument types across different diabetic retinopathy stages in 6 selected peripheral hospitals in Bangladesh from July 2017 to June 2018.

\begin{tabular}{lll}
\hline Stage of diabetic retinopathy & Sensitivity/specificity $(\%)$ of hand-held camera & Sensitivity/specificity (\%) of desk-based camera \\
\hline No diabetic retinopathy & $85.59(56.50)$ & $87.20(93.00)$ \\
Mild NPDR & $59.26(92.09)$ \\
Moderate NPDR & $69.35(62.17)$ & $49.02(96.91)$ \\
Severe NPDR & $50.75(92.53)$ & $72.00(93.03)$ \\
PDR $^{\mathrm{b}}$ & $52.00(96.37)$ & $49.02(99.52)$ \\
\hline
\end{tabular}

${ }^{a}$ NPDR: nonproliferative diabetic retinopathy.

${ }^{\mathrm{b}}$ PDR: proliferative diabetic retinopathy.

\section{Determinants of Diabetic Retinopathy}

Table 4 shows the determinants of diabetic retinopathy identified through bivariate and logistic regression analyses. Patient's age, education, BMI, diabetes duration, and controlled blood sugar levels were significant factors at $5 \%$ significance level while predicting diabetic retinopathy occurrence. After controlling for all significant covariates from bivariate results, the probability of diabetic retinopathy was found to increase with increasing educational level, BMI, duration of diabetes for more than 5 years, and uncontrolled blood sugar levels. A graded response was observed between longer duration of diabetes and probability of diabetic retinopathy occurrence. However, BMI showed a negative association with diabetic retinopathy; the odds of having diabetic retinopathy decreased significantly with high BMI (OR 0.59, 95\% CI 0.43-0.81) compared to the reference group consisting of normal weight and underweight patients. 
Table 4. Factors associated with diabetic retinopathy occurrence in Bangladesh from July 2017 to June 2018.

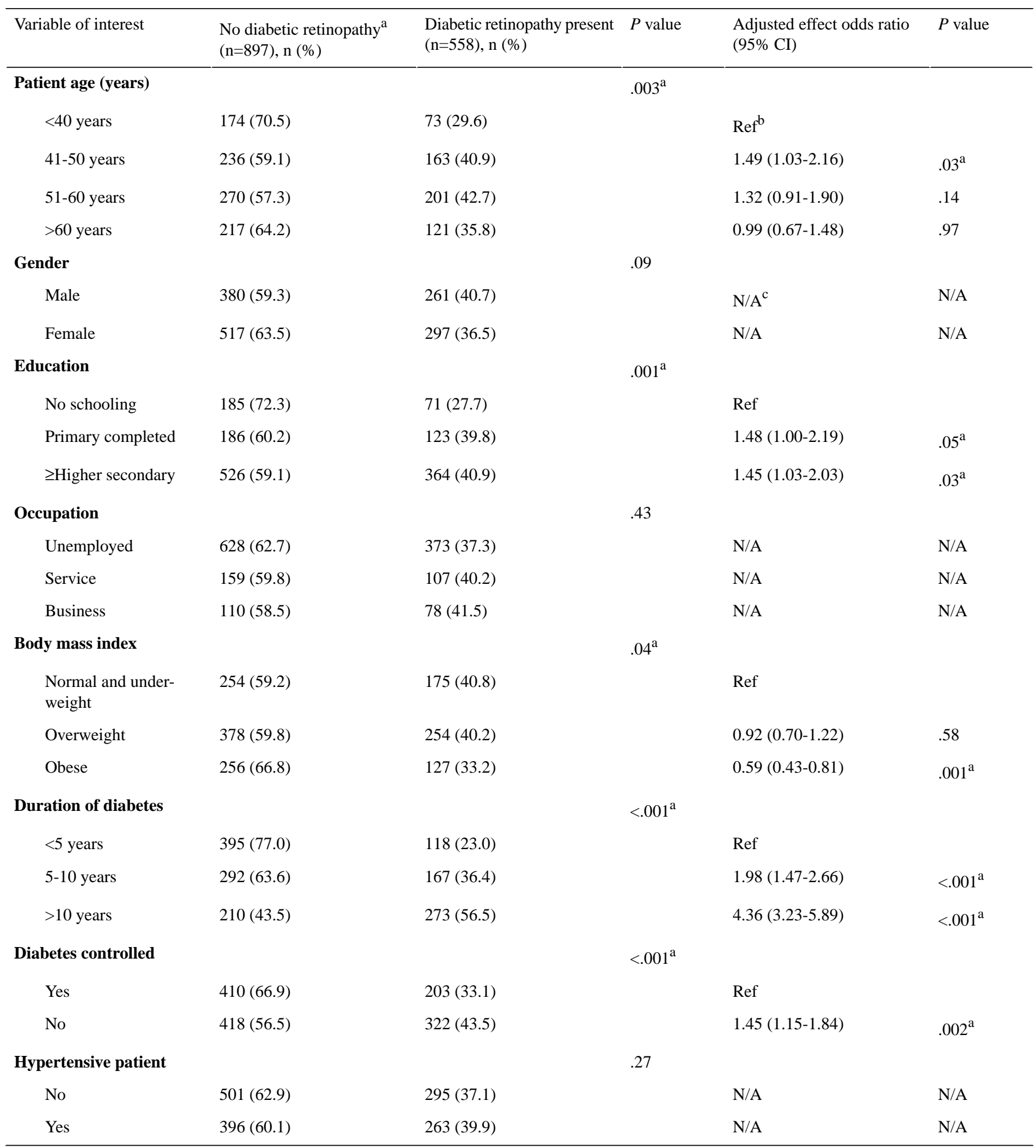

${ }^{\text {a }}$ Results are significant at $P<.05$.

${ }^{\mathrm{b}}$ Ref: reference category, that is, $<40$ years, no schooling, normal and underweight category of BMI, diabetes duration $<5$ years and diabetes controlled for the corresponding covariates. Diabetic retinopathy present was the reference value for the outcome variable.

${ }^{\mathrm{c}} \mathrm{N} / \mathrm{A}$ : not applicable. Implies not included in the multivariate model.

\section{Discussion}

Conducted in 6 peripheral health facilities in Bangladesh, this validation study showed that non-ophthalmologists can detect the presence of diabetic retinopathy with reasonable diagnostic accuracy. The sensitivity and specificity of using a single-field macular photograph after pupillary dilatation against the referral gold standard diagnosis by an eye consultant were $86.6 \%$ (483/558) and 78.6\% (705/897), respectively. The degree of diagnostic agreement between a non-ophthalmologist and an 
ophthalmologist was excellent with a desk-based camera and satisfactory with a hand-held camera.

To our knowledge, this is the first ever study in Bangladesh to engage health care personnel other than eye consultants in routine retinal examination. The reported true positive diabetic retinopathy case detection rate was within the international standard of more than $80 \%$ [21,22]. However, our overall specificity $(79 \%)$ was lower than the international recommendation of $90 \%-95 \%$ [21,22]. This implies that $19.9 \%$ $(173 / 869)$ of the total diabetic retinopathy negative cases were referred to an eye consultant when they did not have diabetic retinopathy [26]. In generic terms, lower specificity implies greater health system burden with a greater number of false positive cases referred to the next level [26]. Nevertheless, in a country like Bangladesh where no formal diabetic retinopathy screening services are available, a large proportion of people with diabetes remain undiagnosed until opportunistic diagnosis occurs at a very advanced stage [28]. Considering the increasing burden of diabetic retinopathy, this will result in increasing eye care-related costs and a greater risk of blindness [29]. By training and engaging non-ophthalmologist health staff in diabetic retinopathy screening, limited resources can be maximized and coverage increased [25]. However, evidence to support the incorporation of non-ophthalmologists into the diabetic retinopathy screening pathway remains scarce in lowand middle-income settings [30]. Some studies in India, Sri Lanka, and Pakistan report satisfactory test accuracy for non-ophthalmologist screening [6,9,31,32]. Using digital fundus photographs and a nonmydriatic approach, "physician graders" in Sri Lanka showed a sensitivity of $88.7 \%$ and specificity of $94.9 \%$ [10]. In Pakistan, optometrists showed $72 \%$ sensitivity and $86.3 \%$ specificity [32]. A decision must also be made about which instrument and imaging technique to use and whether to dilate or not dilate [33]. We validated the diagnostic agreement of hand-held versus desk-based cameras by calculating the AUROC and kappa values. The AUROC was "close to 1" for both instruments [26], suggesting a fair-to-excellent amount of agreement. However, in low- and middle-income country settings, instrument costs should also be considered. Here, the hand-held camera performs better-being comparatively less expensive than a desk-based camera and easier to carry and employ in the context of community-level screening [34].

The variation in test accuracy by instrument type further emphasizes the need to explore other factors influencing diagnostic test accuracy. Here, the gradeability of images plays an important part in successful diabetic retinopathy screening. In this study, a lower rate of ungradable images was reported $(56 / 1511,4.1 \%)$ than that reported in similar health facility-based studies in the South Asian context. A technical failure rate of $7.5 \%$ was noted in another study in Bangladesh [35], which rose to $12 \%$ in Sri Lanka [10]. The higher level of gradeability observed in our study is probably a function of the exclusion criteria or the image-taking technique that was employed. Considering the higher prevalence of cataracts in low-income country settings $[29,36]$, we made the presence of cataract an exclusion criterion in our sample selection and chose to deploy a mydriatic approach for imaging. Although the gold standard for diabetic retinopathy screening is a 7-field photograph using a nonmydriatic approach [37], the applicability of this technique in low-income country settings is highly controversial [38]. When using a nonmydriatic approach, the body's autonomic nervous system becomes hyperactive with reflex pupillary constriction in the second eye after taking an image of the first eye [39,40]. Further, a Brazilian study showed that longer screening time and more referrals to ophthalmologists occurred in the absence of pupil dilation due to a larger number of ungradable images [41]. Further supporting our approach is the evidence of increased provider compliance when using a single-field photograph [42].

To identify other factors affecting diabetic retinopathy diagnosis, we compared test accuracy across different cadres of non-ophthalmologist personnel. We observed that nurses and paramedics showed higher accuracy in detecting any form of diabetic retinopathy than the nonclinical trained staff [43]. The relatively poorer performance of the nonclinical trained staff may be due to their lack of comfort with the hand-held camera. We expect that with more onsite supportive training, performance can be increased. Supporting the call for more hands-on training, a study suggested that the diagnostic accuracy of the fundus camera is highly dependent on the user's technique in taking a correct image and their ability to do proper grading - both of which can be improved with more hands-on support [44]. Variations in the test accuracy by type of provider were similarly observed in a systematic review of 22 observational studies [45]. Noting that the sensitivity of detecting any form of retinopathy using a mydriatic approach ranged between $87 \%$ and $100 \%$ for general practitioners, $>91 \%$ for optometrists, and $89 \%$ and $93 \%$ for ophthalmologists or their assistants, the authors of a study concluded that using appropriate technology and ensuring quality are more important than the type of provider in diabetic retinopathy screening programs [45].

We also explored factors predicting retinopathy occurrence among patients with diabetes. Increased duration of diabetes and obesity were identified as significant predictors of diabetic retinopathy. The odds of having diabetic retinopathy was found to increase 2 times among patients with diabetes for 5-10 years and 4 times among those with diabetes for more than 10 years compared to the odds of having diabetic retinopathy in those with diabetes for less than 5 years. While the increased duration of diabetes for the development of diabetic retinopathy is well-established $[3,8,46,47]$, the observed negative association between obesity and diabetic retinopathy in this study was inconsistent with that reported in the literature. Only 1 study conducted in an urban slum in India reported a similar result; those in the overweight category had lower odds of diabetic retinopathy (OR $0.6,95 \%$ CI $0.4-0.9$ ) than people with normal BMI [31]. In general, however, obesity in the Asian context has been identified as a risk factor for developing diabetic retinopathy [1].

Although results from this pilot study are supportive of mainstreaming non-ophthalmologist health staff in diabetic retinopathy screening services, some limitations in the diagnostic processes need to be considered before generalizing this recommendation to other contexts. One important limitation was our decision to exclude patients with cataract and to employ 
a mydriatic and single-field macular photographic approach due to the pilot nature of this research. In this regard, further clinical trials may be useful for determining the test accuracy by type of health professional, type of instrument used, use of pupil dilation, and number of fields chosen for screening. Finally, recommendations emerging from a study conducted in hospitals with specialized diabetes or eye departments may be less pertinent in nonspecialist hospitals where the prevalence of diabetic retinopathy is likely lower.

Considering the rising burden of diabetes in Bangladesh, routine retinal screening of patients with diabetes is not feasible by eye consultants alone. Our study results suggest that non-ophthalmologist staff such as nurses and paramedics could function as frontline health workers in diabetic retinopathy screening programs. As the first step, the engagement of non-ophthalmologist cadres in diabetic retinopathy screening should be limited to categorization based on the presence or absence of diabetic retinopathy only. Their involvement in the more technical area of diabetic retinopathy grading requires further specific training and health system level support. Regarding instrument choice, although the desk-based camera shows better accuracy in detecting diabetic retinopathy, the choice of instrument type should be a function of the capacity of the health facility and the health care provider performing the diagnosis.

\section{Acknowledgments}

We received assistance from Md Rajibul Islam and Dr. Lal B Rawal, former Research Fellow and Senior Associate in Research of icddr,b, Dhaka, Bangladesh, respectively. We would like to acknowledge their contributions during the early phase of project implementation. The financial support to conduct this research was obtained from the Fred Hollow Foundation, Bangladesh through a competitive research grant proposal.

\section{Authors' Contributions}

TB, IA, AA, and AR developed the research proposal. TB, DN, and SI curated the data. TB, DN, and AR analyzed the data. All authors drafted, wrote, reviewed, and approved the final manuscript.

\section{Conflicts of Interest}

None declared.

\section{References}

1. Bourne RRA, Stevens GA, White RA, Smith JL, Flaxman SR, Price H, et al. Causes of vision loss worldwide, 1990-2010: a systematic analysis. The Lancet Global Health 2013 Dec;1(6):e339-e349. [doi: 10.1016/s2214-109x(13)70113-x]

2. Saeedi P, Petersohn I, Salpea P, Malanda B, Karuranga S, Unwin N, IDF Diabetes Atlas Committee. Global and regional diabetes prevalence estimates for 2019 and projections for 2030 and 2045: Results from the International Diabetes Federation Diabetes Atlas, 9 edition. Diabetes Res Clin Pract 2019 Nov;157:107843. [doi: 10.1016/j.diabres.2019.107843] [Medline: 31518657]

3. Yau JWY, Rogers SL, Kawasaki R, Lamoureux EL, Kowalski JW, Bek T, Meta-Analysis for Eye Disease (META-EYE) Study Group. Global prevalence and major risk factors of diabetic retinopathy. Diabetes Care 2012 Mar;35(3):556-564 [FREE Full text] [doi: 10.2337/dc11-1909] [Medline: 22301125]

4. Klein BEK. Overview of epidemiologic studies of diabetic retinopathy. Ophthalmic Epidemiol 2007;14(4):179-183. [doi: 10.1080/09286580701396720] [Medline: 17896294]

5. Fong DS, Aiello L, Gardner TW, King GL, Blankenship G, Cavallerano JD, American Diabetes Association. Retinopathy in diabetes. Diabetes Care 2004 Jan;27 Suppl 1:S84-S87. [doi: 10.2337/diacare.27.2007.s84] [Medline: 14693935]

6. Gupta V, Bansal R, Gupta A, Bhansali A. Sensitivity and specificity of nonmydriatic digital imaging in screening diabetic retinopathy in Indian eyes. Indian J Ophthalmol 2014 Aug;62(8):851-856 [FREE Full text] [doi: 10.4103/0301-4738.141039] [Medline: 25230960]

7. Raman R, Srinivasan S, Roy R. Screening practices for diabetic retinopathy. Expert Review of Ophthalmology 2015 Aug 03;10(6):519-521. [doi: 10.1586/17469899.2015.1073108]

8. Lin S, Ramulu P, Lamoureux EL, Sabanayagam C. Addressing risk factors, screening, and preventative treatment for diabetic retinopathy in developing countries: a review. Clin Exp Ophthalmol 2016 May;44(4):300-320. [doi: 10.1111/ceo.12745] [Medline: 26991970]

9. Piyasena MMPN, Murthy GVS, Yip JLY, Gilbert C, Zuurmond M, Peto T, et al. Systematic review on barriers and enablers for access to diabetic retinopathy screening services in different income settings. PLoS One 2019;14(4):e0198979 [FREE Full text] [doi: 10.1371/journal.pone.0198979] [Medline: $\underline{\text { 31013274] }}$

10. Piyasena MMPN, Yip JLY, MacLeod D, Kim M, Gudlavalleti VSM. Diagnostic test accuracy of diabetic retinopathy screening by physician graders using a hand-held non-mydriatic retinal camera at a tertiary level medical clinic. BMC Ophthalmol 2019 Apr 08;19(1):89 [FRE Full text] [doi: 10.1186/s12886-019-1092-3] [Medline: $\underline{30961576]}$

11. Hutchinson A, McIntosh A, Peters J, O'Keeffe C, Khunti K, Baker R, et al. Effectiveness of screening and monitoring tests for diabetic retinopathy--a systematic review. Diabet Med 2000 Jul;17(7):495-506. [doi: 10.1046/j.1464-5491.2000.00250.x] [Medline: 10972578 ] 
12. Gulshan V, Peng L, Coram M, Stumpe MC, Wu D, Narayanaswamy A, et al. Development and Validation of a Deep Learning Algorithm for Detection of Diabetic Retinopathy in Retinal Fundus Photographs. JAMA 2016 Dec 13;316(22):2402-2410. [doi: $\underline{10.1001 / j a m a .2016 .17216]}$ [Medline: $\underline{27898976}$ ]

13. Bu D, Pan E, Walker J, Adler-Milstein J, Kendrick D, Hook JM, et al. Benefits of information technology-enabled diabetes management. Diabetes Care 2007 May;30(5):1137-1142. [doi: 10.2337/dc06-2101] [Medline: 17322483]

14. Baeza M, Orozco-Beltrán D, Gil-Guillen VF, Pedrera V, Ribera MC, Pertusa S, et al. Screening for sight threatening diabetic retinopathy using non-mydriatic retinal camera in a primary care setting: to dilate or not to dilate? Int J Clin Pract 2009 Mar;63(3):433-438. [doi: 10.1111/j.1742-1241.2008.01921.x] [Medline: 19222628]

15. International Diabetes Federation Diabetes Atlas eighth edition. 2017. URL: https://www.diabetesatlas.org [accessed 2019-11-07]

16. Performance Report (2009-2010) and HRD (2011)/HRH (2013,2014) Data Sheet. Ministry of Health and Family Welfare, Government of the People's Republic of Bangladesh. URL: http://www.mohfw.gov.bd/index.php?option=com content\&view=article\&id=112 [accessed 2019-11-07]

17. Islam SMS, Tabassum R, Colet P, Cruz JP. Human resources for non-communicable diseases in Bangladesh. International Journal of Perceptions in Public Health 2017;1(2):98-101.

18. Sayeed MA, Rahman AS, Ali MH, Rhaman MM, Haq JA, Banu A. Diabetic retinopathy and visual impairment in disaster prone coastal population of Bangladesh. IMC J Med Sci 2017 Jan 12;10(1):10-17. [doi: 10.3329/imcjms.v10i1.31100]

19. Thapa R, Twyana SN, Paudyal G, Khanal S, van Nispen R, Tan HS, et al. Prevalence and risk factors of diabetic retinopathy among an elderly population with diabetes in Nepal: the Bhaktapur Retina Study. Opth 2018 Mar;Volume 12:561-568. [doi: $10.2147 /$ opth.s157560]

20. Malhotra R, Indrayan A. A simple nomogram for sample size for estimating sensitivity and specificity of medical tests. Indian J Ophthalmol 2010;58(6):519-522 [FREE Full text] [doi: 10.4103/0301-4738.71699] [Medline: 20952837]

21. Harding S, Greenwood R, Aldington S, Gibson J, Owens D, Taylor R, Diabetic Retinopathy GradingDisease Management Working Party. Grading and disease management in national screening for diabetic retinopathy in England and Wales. Diabet Med 2003 Dec;20(12):965-971. [doi: 10.1111/j.1464-5491.2003.01077.x] [Medline: 14632697]

22. Hooper P, Boucher MC, Cruess A, Dawson KG, Delpero W, Greve M, et al. Canadian Ophthalmological Society evidence-based clinical practice guidelines for the management of diabetic retinopathy. Can J Ophthalmol 2012 Apr;47(2 Suppl):S1-30, S31. [doi: 10.1016/j.jcjo.2011.12.025] [Medline: 22632804]

23. Global strategy on diet, physical activity and health: a framework to monitor and evaluate implementation. World Health Organization. 2006. URL: https://apps.who.int/iris/handle/10665/43524 [accessed 2017-05-06]

24. American Diabetes Association. Classification and Diagnosis of Diabetes. Diabetes Care 2020 Jan;43(Suppl 1):S14-S31. [doi: $10.2337 / \mathrm{dc} 20-$ S002] [Medline: $\underline{31862745]}$

25. Trevethan R. Sensitivity, Specificity, and Predictive Values: Foundations, Pliabilities, and Pitfalls in Research and Practice. Front Public Health 2017;5:307 [FREE Full text] [doi: 10.3389/fpubh.2017.00307] [Medline: 29209603]

26. Florkowski C. Sensitivity, specificity, receiver-operating characteristic (ROC) curves and likelihood ratios: communicating the performance of diagnostic tests. Clin Biochem Rev 2008 Aug;29 Suppl 1:S83-S87. [Medline: 18852864]

27. Citing Stata software, documentation, and FAQs. STATACorp Release 16. College Station, TX: StataCorp LLC; 2019. URL: https://www.stata.com/support/faqs/resources/citing-software-documentation-faqs/ [accessed 2019-11-19]

28. Diabetes retinopathy prevalent in Bangladesh. 2014. URL: https://www.diabetes.co.uk/news/2014/oct/ diabetes-retinopathy-prevalent-in-bangladesh-99436687.html [accessed 2019-09-16]

29. Stevens GA, White RA, Flaxman SR, Price H, Jonas JB, Keeffe J, Vision Loss Expert Group. Global prevalence of vision impairment and blindness: magnitude and temporal trends, 1990-2010. Ophthalmology 2013 Dec;120(12):2377-2384. [doi: 10.1016/j.ophtha.2013.05.025] [Medline: 23850093]

30. Piyasena MMPN, Murthy GVS, Yip JLY, Gilbert C, Peto T, Gordon I, et al. Systematic review and meta-analysis of diagnostic accuracy of detection of any level of diabetic retinopathy using digital retinal imaging. Syst Rev 2018 Nov 07;7(1):182 [FREE Full text] [doi: 10.1186/s13643-018-0846-y] [Medline: 30404665]

31. Wadhwani M, Vashist P, Singh SS, Gupta N, Malhotra S, Gupta A, et al. Diabetic retinopathy screening programme utilising non-mydriatic fundus imaging in slum populations of New Delhi, India. Trop Med Int Health 2018 Apr;23(4):405-414 [FREE Full text] [doi: 10.1111/tmi.13039] [Medline: 29430785]

32. Fahadullah M, Memon N, Salim S, Ahsan S, Fahim MF, Mumtaz SN, et al. Diagnostic accuracy of non-mydriatic fundus camera for screening of diabetic retinopathy: A hospital based observational study in Pakistan. J Pak Med Assoc 2019 Mar;69(3):378-382 [FREE Full text] [Medline: 30890831]

33. Martínez-Vizcaíno V, Cavero-Redondo I, Álvarez-Bueno C, Rodríguez-Artalejo F. The Accuracy of Diagnostic Methods for Diabetic Retinopathy: A Systematic Review and Meta-Analysis. PLoS One 2016;11(4):e0154411 [FREE Full text] [doi: 10.1371/journal.pone.0154411] [Medline: 27123641]

34. Scarpa G, Urban F, Vujosevic S, Tessarin M, Gallo G, Visentin A, et al. The Nonmydriatic Fundus Camera in Diabetic Retinopathy Screening: A Cost-Effective Study with Evaluation for Future Large-Scale Application. J Ophthalmol 2016;2016:4625096 [FREE Full text] [doi: 10.1155/2016/4625096] [Medline: 27885337] 
35. Ahsan S, Basit A, Ahmed KR, Ali L, Shaheen F, Ulhaque MS, et al. Diagnostic accuracy of direct ophthalmoscopy for detection of diabetic retinopathy using fundus photographs as a reference standard. Diabetes Metab Syndr 2014;8(2):96-101. [doi: 10.1016/j.dsx.2014.04.015] [Medline: 24907174]

36. Khairallah M, Kahloun R, Bourne R, Limburg H, Flaxman SR, Jonas JB, Vision Loss Expert Group of the Global Burden of Disease Study. Number of People Blind or Visually Impaired by Cataract Worldwide and in World Regions, 1990 to 2010. Invest Ophthalmol Vis Sci 2015 Oct;56(11):6762-6769. [doi: 10.1167/iovs.15-17201] [Medline: 26567788]

37. Roser P, Kalscheuer H, Groener JB, Lehnhoff D, Klein R, Auffarth GU, et al. Diabetic Retinopathy Screening Ratio Is Improved When Using a Digital, Nonmydriatic Fundus Camera Onsite in a Diabetes Outpatient Clinic. J Diabetes Res 2016;2016:4101890 [FREE Full text] [doi: 10.1155/2016/4101890] [Medline: 26904690]

38. Li HK, Horton M, Bursell SE, Cavallerano J, Zimmer-Galler I, Tennant M, American Telemedicine Association Diabetic Retinopathy Telehealth Practice Recommendations Working Group, et al. Telehealth practice recommendations for diabetic retinopathy, second edition. Telemed J E Health 2011 Dec;17(10):814-837 [FREE Full text] [doi: 10.1089/tmj.2011.0075] [Medline: 21970573]

39. Perrier M, Boucher MC, Angioi K, Gresset JA, Olivier S. Comparison of two, three and four $45^{\circ}$ image fields obtained with the Topcon CRW6 nonmydriatic camera for screening for diabetic retinopathy. Canadian Journal of Ophthalmology 2003 Dec;38(7):569-574. [doi: 10.1016/s0008-4182(03)80110-2]

40. Liesenfeld B, Kohner E, Piehlmeier W, Kluthe S, Aldington S, Porta M, et al. A telemedical approach to the screening of diabetic retinopathy: digital fundus photography. Diabetes Care 2000 Mar;23(3):345-348 [FREE Full text] [doi: 10.2337/diacare.23.3.345] [Medline: 10868863]

41. Quellec G, Bazin L, Cazuguel G, Delafoy I, Cochener B, Lamard M. Suitability of a Low-Cost, Handheld, Nonmydriatic Retinograph for Diabetic Retinopathy Diagnosis. Transl Vis Sci Technol 2016 Apr;5(2):16 [FREE Full text] [doi: 10.1167/tvst.5.2.16] [Medline: 27134775]

42. Williams GA, Scott IU, Haller JA, Maguire AM, Marcus D, McDonald H. Single-field fundus photography for diabetic retinopathy screening: a report by the American Academy of Ophthalmology. Ophthalmology 2004 May;111(5):1055-1062. [doi: 10.1016/j.ophtha.2004.02.004] [Medline: 15121388]

43. Šimundić AM. Measures of Diagnostic Accuracy: Basic Definitions. EJIFCC 2009 Jan;19(4):203-211 [FREE Full text] [Medline: 27683318]

44. Ahmed J, Ward TP, Bursell S, Aiello LM, Cavallerano JD, Vigersky RA. The sensitivity and specificity of nonmydriatic digital stereoscopic retinal imaging in detecting diabetic retinopathy. Diabetes Care 2006 Oct;29(10):2205-2209. [doi: 10.2337/dc06-0295] [Medline: 17003294]

45. Montori VM. Mydriatic retinal photography is the most effective test for detecting diabetic retinopathy. BMJ 2001 Mar;6(2):56-56. [doi: 10.1136/ebm.6.2.56]

46. Varma R, Choudhury F, Klein R, Chung J, Torres M, Azen SP, Los Angeles Latino Eye Study Group. Four-year incidence and progression of diabetic retinopathy and macular edema: the Los Angeles Latino Eye Study. Am J Ophthalmol 2010 May;149(5):752-61.e1 [FREE Full text] [doi: 10.1016/j.ajo.2009.11.014] [Medline: 20149342]

47. Ding J, Wong TY. Current epidemiology of diabetic retinopathy and diabetic macular edema. Curr Diab Rep 2012 Aug;12(4):346-354. [doi: 10.1007/s11892-012-0283-6] [Medline: 22585044]

\section{Abbreviations \\ AUROC: area under the receiver operating curve \\ DAB: Diabetic Association of Bangladesh \\ FHF: Fred Hollows Foundation \\ OR: odds ratio}

Edited by T Sanchez; submitted 15.08.20; peer-reviewed by S Rahman, G Lim; comments to author 11.09.20; revised version received
01.11.20; accepted 16.12.20; published 09.03.21
Please cite as:
Begum T, Rahman A, Nomani D, Mamun A, Adams A, Islam S, Khair Z, Khair Z, Anwar I
Diagnostic Accuracy of Detecting Diabetic Retinopathy by Using Digital Fundus Photographs in the Peripheral Health Facilities of
Bangladesh: Validation Study
JMIR Public Health Surveill 2021;7(3):e 23538
URL: $\underline{\text { https://publichealth.jmir.org/2021/3/e23538 }}$
doi: $\underline{10.2196 / 23538}$
PMID: $\underline{33411671}$


(C)Tahmina Begum, Aminur Rahman, Dilruba Nomani, Abdullah Mamun, Alayne Adams, Shafiqul Islam, Zara Khair, Zareen Khair, Iqbal Anwar. Originally published in JMIR Public Health and Surveillance (http://publichealth.jmir.org), 09.03.2021. This is an open-access article distributed under the terms of the Creative Commons Attribution License (https://creativecommons.org/licenses/by/4.0/), which permits unrestricted use, distribution, and reproduction in any medium, provided the original work, first published in JMIR Public Health and Surveillance, is properly cited. The complete bibliographic information, a link to the original publication on http://publichealth.jmir.org, as well as this copyright and license information must be included. 